\title{
LOS ORADORES ÁTICOS Y ALGUNOS TÉRMINOS JURÍDICOS: \\ CONDICIONAMIENTOS DISTRIBUCIONALES Y PREFIJALES
}

INÉS CALERO SECALL

Universidad de Málaga ines@uma.es

Este trabajo estudia algunos términos provistos del preverbio غ̇ंí que aparecen en los textos de los oradores áticos del siglo IV a.C. Este análisis demuestra que no sólo el preverbio, sino también el contexto, la oposición entre activa y media y las diferentes clases de personas que constituyen el sujeto de algunos verbos influyen en el significado. Además se examina si estos vocablos están usados exclusivamente como términos técnicos jurídicos o no.

Palabras clave: Términos jurídicos, preverbio ėđí, oradores áticos
This paper studies some juridical words, provided with the preverb é $\pi$ í, that appear in the Attic Orators' texts in the fourth century B.C. This analysis shows that not only the preverb, but also the context, the opposition between the active and middle, and the different classes of people which form the subject of some verbs influence the meaning. Moreover it is examined if these words are exclusively used as juridical technical terms or not.

Keywords: Juridical words, preverb غ̇ंí, Attic Orators

Con el convencimiento de que la Filología contribuye en gran manera a la comprensión jurídica ${ }^{1}$ y de que la observación de los detalles sintácticos es imprescindible para una precisa interpretación semántica, me propongo estudiar algunos términos jurídicos que aparecen en los textos de los oradores áticos del siglo IV para conocer con mayor exactitud la aplicación jurídica de tales vocablos en el derecho de Atenas ${ }^{2}$.

Pues bien, una lectura detenida de sus discursos me ha llevado a ver que la prefijación influye de una forma nada despreciable en la significación legal del término, de modo que con frecuencia se emplea como recurso la

1. Sobre la necesidad de intercambio de conocimientos entre el filólogo y el jurista, cf. H. B. Rosén, «Questions d' interprétation de textes juridiques grecs de la plus ancienne époque», Symposion 1977, AGR, Köln, 1982, p. 9.

2 Sobre el tema del vocabulario jurídico griego es interesante consultar el trabajo de J. $\mathrm{M}^{\mathrm{a}}$. Lucas, «Consideraciones generales sobre el vocabulario jurídico griego», Epos 2, 1986, pp. 187-204, quien, en contra de lo que se piensa, cree en la existencia de «una clara tendencia en la lengua griega a ir consolidando un vocabulario jurídico», p. 187. 
oposición entre el simple y el compuesto para obtener diferentes matices. Pero además no sólo la prefijación, sino también la distribución han desempeñado un considerable papel en el sentido jurídico de un término, puesto que los componentes que integran la distribución de una frase son determinantes y, por ello, es fundamental el examen del contexto.

Partimos de la base de que «un signo tiene un significado en un determinado contexto, en otros puede tener otro» ${ }^{3}$, y máxime si tenemos en cuenta la importancia en materia jurídica de las personas que constituyen el emisor o el receptor.

Por razones obvias de extensión nos vamos a limitar a examinar sólo los términos prefijados con غ̇лí, cuyo empleo fue bastante productivo, centrándonos, sobre todo, en las formas verbales y su familia léxica que entraron a formar parte del vocabulario jurídico. Se ha de decir que la mayoría de los términos verbales manejados no tiene un uso exclusivamente técnico, sino que, junto a un significado propio de la lengua común, coexiste un sentido específico en el campo jurídico y, en cambio, los términos nominales de la misma familia son, por lo general, los que se consagran como tecnicismo legal.

Estamos ante uno de los prefijos dilectos de la lengua jurídica que lo utilizó con diferentes valores para precisar su léxico, dado que en función de preverbio como "lleno" que es, utilizando la terminología tradicional de Humbert ${ }^{4}$, aporta unas connotaciones semánticas determinadas al lexema verbal o nominal.

Teniendo en cuenta la clasificación de los usos de las preposiciones que comparten tanto el Funcionalismo de $\mathrm{Dik}^{5}$ como el método estructural y al mismo tiempo funcional que propone el profesor Adrados en su Nueva Sinta$x i s$, aunque con denominaciones similares, dado que el valor o función espacial, temporal y abstracto ${ }^{6}$, como distingue el Funcionalismo, viene a ser lo mismo que el uso local, temporal y nocional, terminología utilizada por Adra$\operatorname{dos}^{7}$, vamos a aplicarla a los preverbios en la idea de que son preposiciones

3 F. Rodríguez Adrados, Nueva sintaxis del griego antiguo, Madrid, 1992, p. 23.

J. Humbert, Syntaxe Grecque, Paris, 1972, p. 337.

S. C. Dik, Functional Grammar, Amsterdam, 1978 y The Theory of Functional Grammar, Dordrecht, 1989.

6 J. de la Villa, «El léxico como determinante de la función: los sintagmas preposicionales que expresan tiempo en Homero», Actas del VIII Congreso Español de Estudios Clásicos, Madrid, 1994, p. 331.

7 Rodríguez Adrados, ob. cit., p. 720.

EMERITA (EM) LXXV 1, enero-junio $2007 \quad$ pp. 113-136 ISSN 0013-6662 
aglutinadas al verbo o a una clase de palabra del sintagma nominal ${ }^{8}$.

A veces no hay una línea divisoria clara entre los usos, siendo, por supuesto, el nocional el más difícil de clasificar ${ }^{9}$. Entiendo además que esos distintos usos no han de ser considerados derivados, sino que coexisten, como ya vio Brondal y Pottier ${ }^{10}$, al que se adhiere el trabajo de $\mathrm{M}^{\mathrm{a}}$ Ángeles Martínez Valladares ${ }^{11}$. Sin ir más lejos, este prefijo, unido a una misma raíz, puede adquirir en un mismo autor dos valores, p. ej. el temporal y nocional

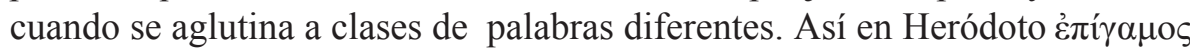

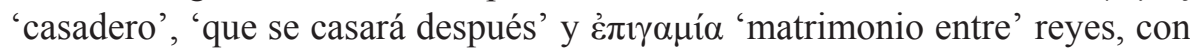
valor figurado de reciprocidad (cf. Liddell-Scott-Jones).

Dentro del empleo local asumo la distinción de dos valores en غ̇ंí que observa Ruijgh: el valor 'sobre' y 'cerca', غ̇лí SUR y غ̇ंí PRES, subyaciendo en el primero un contacto vertical, mientras que en el segundo «un contacto horizontal o al menos no vertical» ${ }^{12}$.

Pues bien, hemos observado que existen vocablos nominales con un marcado sentido técnico en relación con raíces verbales que no comportan un valor jurídico, y en los que la influencia del prefijo ha sido determinante en

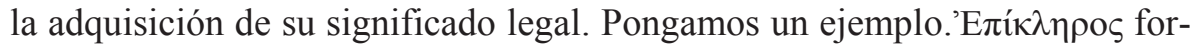
mado de $\kappa \lambda \tilde{\eta} \rho \circ \varsigma$ significa 'heredera'. Se trata de la hija única huérfana que transmite los bienes de su padre a sus hijos cuando éstos llegan a la mayoría de edad. Ella ha de ser entregada en matrimonio, junto a los bienes, al pariente más próximo, por lo que literalmente epiclera equivale a 'sobre el kleros', pero en realidad la connotación que aporta el prefijo es una noción de acompañamiento 'junto al kleros' en la que el prefijo ha sido usado en sentido abstracto (D. 43.20). Esta misma precisión se podría observar en غ̇ंír $\rho 01-$

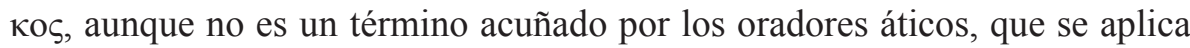
a las otras mujeres que no son herederas. Designa a las hijas que son entrega-

8 En un estudio reciente Silvia Luraghi distingue en $\dot{z} \pi$ í construcciones con los tres casos, donde la preposición puede expresar el locativo, la dirección, haya o no contacto, además de una idea temporal, cf. S. Luraghi, Studi su casi e preposizioni nel greco antico, Milán, 1996, pp. 82, 84.

9 Rodríguez Adrados, ob. cit., p. 723.

10 B. Pottier, Systématique des eléments de relation, Paris, 1962.

11 M. A. Martínez Valladares, «Notas sobre el valor semántico de las preposiciones griegas», Durius, 1976, pp. 221, 222.

12 C. J. Ruijgh, «La préposition غ̇ंí. Valeurs sémantiques et choix des cas», en B. Jacquinod (ed.), Cas et prépositions en Grec Ancien. Actes du Colloque International de Saint-Étienne, Saint-Étienne, 1994, p. 134.

EMERITA (EM) LXXV 1, enero-junio $2007 \quad$ pp. 113-136 ISSN 0013-6662 
das 'sobre la dote', 'con la dote'.

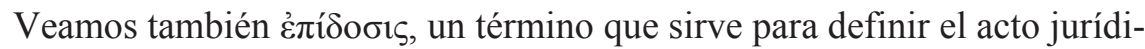
co de la donación. Ese acto de liberalidad por el que una persona se desprende de parte de su patrimonio a favor de otra supone una entrega gratuita ${ }^{13}$ de bienes sin ninguna obligación. El prefijo en este caso añadiría el matiz de 'gratuidad' al tener un uso nocional indicando 'además'. En Demóstenes lo vemos en alusión a los ciudadanos que tenían la posibilidad de costear con su dinero trirremes (D. 21.161).

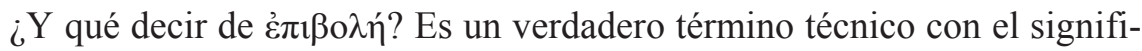
cado de 'multa'. De la misma raíz de $\beta \alpha ́ \alpha \lambda \omega$, en este nombre se produjo un desplazamiento del sentido concreto al figurado. Frente al nombre de acción $\beta 0 \lambda \eta ́$, en el compuesto con غ̇ंí sigue subyaciendo la noción de 'lanzar' en el sentido legal de 'multa', donde el preverbio tiene mucho que decir. El prefijo interviene con una clara connotación semántica de hostilidad, una noción de interés de forma negativa. En el lenguaje jurídico tiene aún una precisión mayor, porque a غ̇лıßoдń se le otorgó connotaciones especiales en este campo y quedó restringido, sobre todo, a las multas que eran impuestas por los arcontes, frente a غ̇ंıтí $\mu 1 \alpha$, que eran las derivadas del incumplimiento de contratos. De lo que decimos dan buena fe los oradores Lisias, Esquines y Demóstenes.

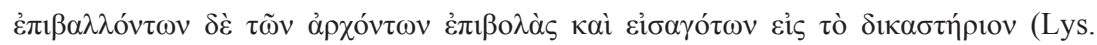
30.3)

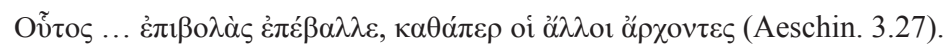

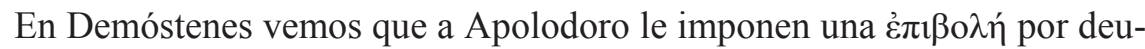
dor y ha de pagar al erario seiscientas diez dracmas (D. 53.14). Precisamente entre las atribuciones de los arcontes que menciona Aristóteles en Ath. 61.2 se encuentra la imposición de multas o żं $ı$ o $\lambda \alpha{ }^{14}$. Beauchet ${ }^{15}$ nos ilustra de la repercusión que ocasionaba el impago de esta multa que motivaba la $\alpha$ đo-

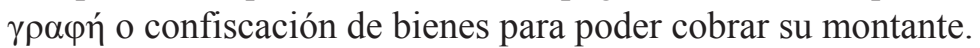

13 D. Roques, «Le vocabulaire politique d' Hérodien», Ktema 15, 1990, p. 57.

14 Que éstas fueran las clases de multas impuestas por una autoridad pública está atestiguado también por una inscripción ática del s. IV a. C (IG II 2.1177) en la que se indica que

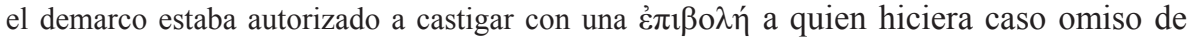

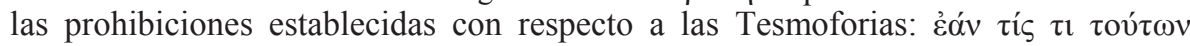

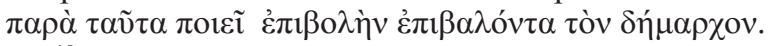

15 L. Beauchet, Histoire du droit privé de la République Athénienne, III, Paris, 1897, p. 420 .

EMERITA (EM) LXXV 1, enero-junio $2007 \quad$ pp. 113-136 ISSN 0013-6662 


\section{FORMAS VERBALES Y SU FAMILIA LÉXICA}

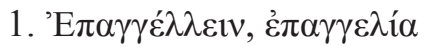

a) Desde Homero al significar tanto $\alpha \gamma \gamma \varepsilon \dot{\lambda} \lambda \lambda \varepsilon ı v$ como $\dot{\varepsilon} \pi \alpha \gamma \gamma \dot{\lambda} \lambda \lambda \varepsilon ı v$ 'anunciar', 'llevar un mensaje', podemos considerar que el preverbio del compuesto estaría neutralizado, aunque tal vez signifique un refuerzo del valor directivo del dativo que indica la persona a la que se anuncia:

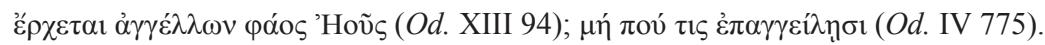

Pero el verbo simple 'anunciar' apenas entró en el vocabulario de los oradores áticos, a excepción de este ejemplo de Iseo:

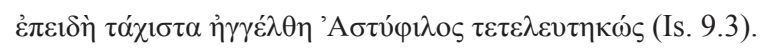

b) En cambio, estos autores prefirieron el compuesto con غ̇ंí, en el que continuaba la idea de 'transmitir un mensaje', pero la distribución influyó en la adquisición de distintos matices semánticos: 1) 'ordenar', 2) 'demandar'.

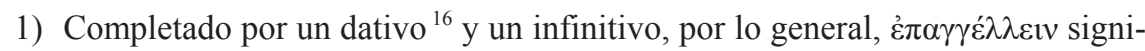
fica 'ordenar', 'notificar', donde la función de sujeto puede venir desempeñada por una persona particular o un magistrado. En este caso continúa con el sentido de la lengua común. Así en la ley sobre el homicidio que intercala Demóstenes en Contra Macártato se prescribe que el demarco ordene a los parientes que procedan al levantamiento y sepultura de los cadáveres:

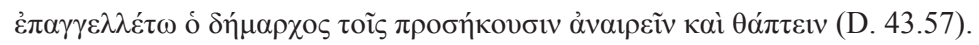

2) Por el contrario, cuando los magistrados son los destinatarios de ese mensaje, $\dot{\varepsilon} \pi \alpha \gamma \gamma \varepsilon \dot{\lambda} \lambda \varepsilon \varepsilon v$ adquiere entonces una connotación ya especialmente jurídica que se incorpora al campo semántico de la denuncia o acusación. Concretamente en los oradores áticos es un término técnico que indica la acción de denunciar y de exigir una dokimasía o investigación ante los Tesmotetas.

Existía una ley que prohibía hacer uso de la palabra en una tribuna a una persona que hubiera sido considerada indigna de ejercer sus derechos cívicos por varias causas, por no haber desempeñado sus deberes militares, por prostituirse, por incumplir sus obligaciones filiales y deber dinero al fisco. El que hubiera incurrido en algunos de estos hechos, en caso de que fuera denunciado, debía someterse a un examen o dokimasía. Así Androción es denunciado por haberse prostituído y por deudas fiscales a consecuencia de lo cual no deberá hacer uso de la tribuna:

16 El papel sintáctico de los casos y de los sintagmas preposicionales en los oradores áticos ha sido estudiado por B. Moreaux, Cas ou tours prepositionnels dans la langue des orateurs attiques. Etude sur la cohesion des sintagmes verbaux, Paris, 1976.

EMERITA (EM) LXXV 1, enero-junio $2007 \quad$ pp. 113-136 ISSN 0013-6662 


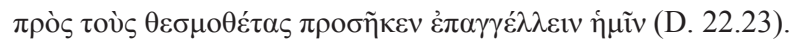

A Timarco también se le niega el derecho de hablar por haber sido acusado de tener costumbres deshonestas y debía someterse a una dokimasía. La expresión más técnica es la empleada por Esquines con una construcción de Ac. + Dat:

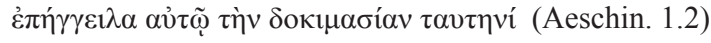

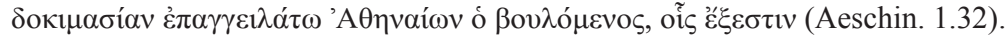

Ahora bien, entre estos dos empleos de $\dot{\pi} \pi \alpha \gamma \gamma \varepsilon \dot{\lambda} \lambda \lambda \varepsilon ı v$ en un uso común y técnico, parece que en el primero 'ordenar' el preverbio poco añade al lexema verbal, mientras que en el sentido de 'denunciar' el preverbio se carga de un valor semántico denotando perjuicio u hostilidad ${ }^{17}$ que subyace en el requerimiento ante los magistrados para que se proceda a la dokimasía, donde el prefijo expresaría la idea de 'contra'.

Estos dos significados del derecho ático son corroborados por Hesiquio que nos dice:

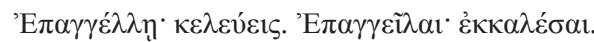

c) De este modo se explica que en el derecho ático se acuñe el vocablo غ̇ं $\alpha \gamma$ $\gamma \varepsilon \lambda i ́ a$ como un término técnico para indicar especialmente esa denuncia o requerimiento que un ciudadano hacía ante los Tesmotetas para que se procediera a un examen o dokimasía de otro ciudadano. Así en Aeschin. 1.81 el término alude a la denuncia contra Timarco por su indignidad para hacer uso de la palabra por haber caído en la condición de átimos:

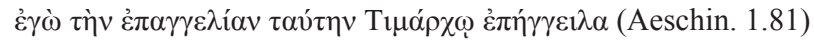

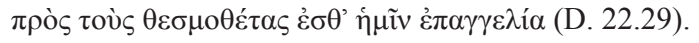

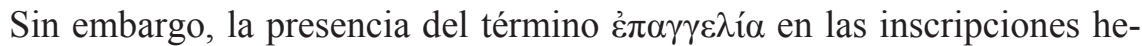
lenísticas ${ }^{18}$ muestra la pérdida de ese sentido tan especial del derecho ático y continúa unido al campo semántico primigenio de la transmisión de un mensaje.

17 Esta expresión semántica es denominada 'Beneficiario' por el análisis funcional, cf. M. D. Jiménez López, «Remarques sur la rection et les prépositions», en B. Jacquinod (ed.), Cas et prépositions en Grec Ancien. Actes du Colloque International de Saint-Étienne, SaintÉtienne, 1994, p. 213, pero me parece más adecuada definirla 'Beneficiario-Oponente', como E. Crespo, «Sintaxis de los elementos de relación en griego clásico», Actas del IX Congreso Español de Estudios Clásicos, II, Madrid, 1997, p. 33, puesto que con esta denominación se recoge la idea de beneficio y perjuicio.

18 IG XII 3. 330, 126.

EMERITA (EM) LXXV 1, enero-junio $2007 \quad$ pp. 113-136 ISSN 0013-6662 


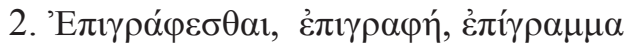

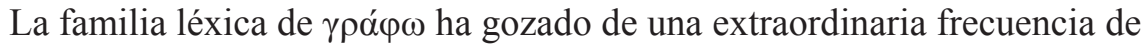
empleo como término legal. Es lógico que fuera así, desde que sirviera, tras su primitivo significado de 'arañar', 'gravar', para indicar toda acción relacionada con la escritura. La profusión de escritos que demandaban los procesos judiciales justifica su uso en la más variada gama de acepciones con un componente nocional de algo manuscrito.

Desde la conocidísima $\gamma \rho \alpha \varphi \eta ́$ instalada en el derecho ático como toda acción pública que, sin duda, era puesta por escrito, hasta los compuestos

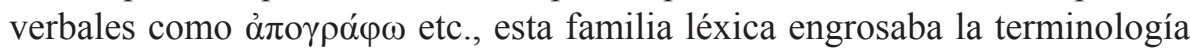
jurídica griega. Con el prefijo غ̇ंí en su uso local 'sobre', se marca el contacto estrecho vertical como diría Ruijgh ${ }^{19}$.

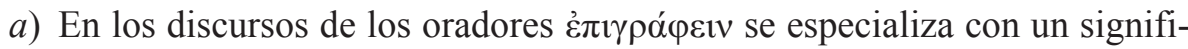
cado legal, por lo general en voz media, de 'registrar' o 'inscribir', como

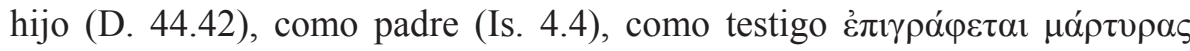

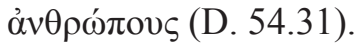

b) Con connotaciones más jurídicas, este compuesto sirvió en el lenguaje procesal para expresar la acción de 'poner por escrito' las multas y los daños estimados en las actas de acusación o las valoraciones de una herencia. Con

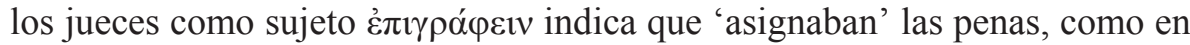

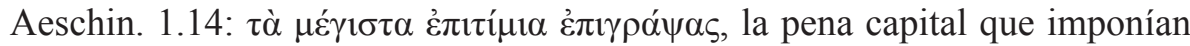
contra el que corrompiera a un niño o a una mujer libre. En Is. 3.2 Xenocles

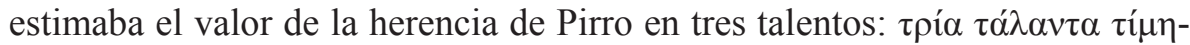

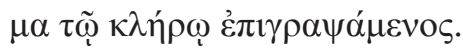

En forma absoluta se encuentra en D. 29.8 cuando en el proceso contra

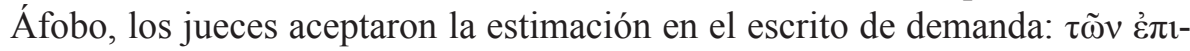

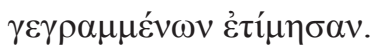

c) Es, sobre todo, el neutro sufijado con $-m a$, غ̇ंír $\rho \alpha \mu \mu \alpha$, el término propia-

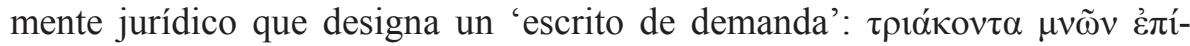
$\gamma \rho \alpha \mu \mu \alpha$ "escrito de demanda de treinta minas" (D. 38.2).

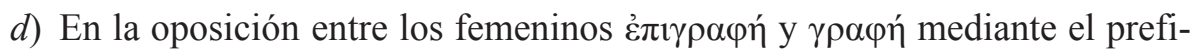
jo, el vocablo simple se polarizó como un tecnicismo especial para designar toda acción pública, mientras que el compuesto se aplicaba con diversas acepciones sin tener un sentido rigurosamente jurídico, como registros de

19 Ruijgh, ob. cit., p. 134.

EMERITA (EM) LXXV 1, enero-junio $2007 \quad$ pp. 113-136 ISSN 0013-6662 
propiedad o de nombres:

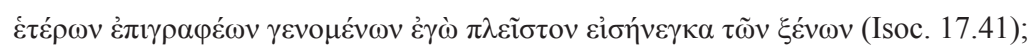

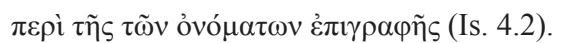

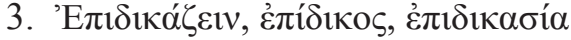

Las clases de palabras que abastece la raíz * dik tuvieron en derecho ático un uso muy difundido con significados no unitarios por causas diversas. Es

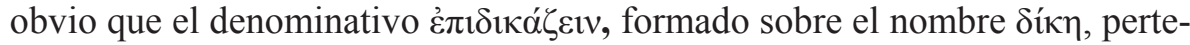
neciera al campo semántico de la Justicia, pero hemos de ver la intervención no sólo de factores distribucionales, sino también de prefijación en el contenido semántico que adquiere.

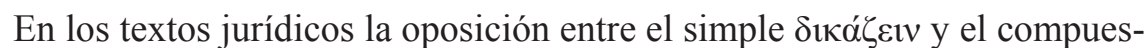
to $\dot{\pi} \imath \delta \iota \kappa a ́ \zeta \varepsilon ı v$ mediante el preverbio debió de servir para expresar un matiz diferente. Y pese a que ambos verbos puedan llevar como sujeto personas de categoría semejante, los atenienses distinguirían perfectamente la precisión judicial que comportaban.

a) En voz activa $\delta$ ¿ $\alpha ́ \zeta \varepsilon ı v$ se dice de aquel que pronuncia un juicio ya sea judicial o no. En los poemas homéricos aparece con bastante frecuencia: Il. VIII 431.

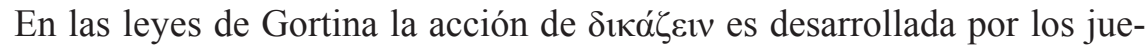
ces, pero no se puede decir que el legislador cretense lo utilizara como un sinónimo de 'juzgar' según su decisión, porque esta connotación es expresa-

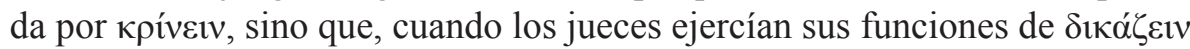
dependían de un procedimiento probatorio sin libertad de decisión ${ }^{20}$.

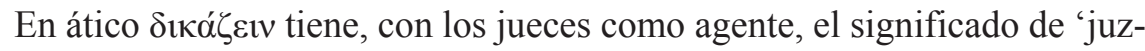
gar' tal como nosotros lo entendemos y como aparece en muchas ocasiones

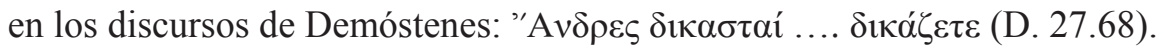

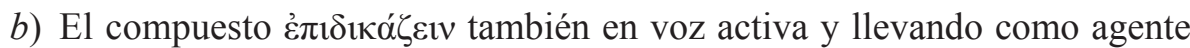
los jueces se consolida con un significado más preciso, que viene determinado no sólo por el prefijo, sino también por la construcción. Mientras que, mediante el simple, se nos dice que los jueces 'desempeñan funciones judiciales', 'juzgan', por el compuesto se manifiesta que 'atribuyen o adjudican judi-

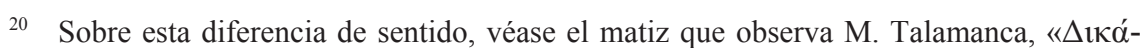

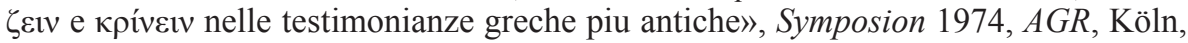
1979, quien aprecia en la acción del juez, cuando кpíveıv, la obligación de hacer un juramento, pp. 104, 120.

EMERITA (EM) LXXV 1, enero-junio $2007 \quad$ pp. 113-136 ISSN 0013-6662 


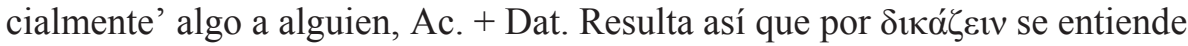
una acción de los jueces más genérica que cuando se emplea el compuesto con $\dot{\varepsilon} \pi$ í, quedando limitado a contextos que aluden a las disputas judiciales que se originaban a causa de la herencia y el matrimonio de la heredera. Es decir, cuando moría el de cuius sin hijos varones, los parientes reclamaban sus derechos a casarse con la hija, dado que esta alianza a la vez llevaba emparejada la adquisición de la herencia. En un litigio la acción que los jueces $^{21}$ realizaban mediante $\dot{\varepsilon} \pi \_\delta \kappa \alpha ́ \zeta \varepsilon ı v$ era 'adjudicar' la herencia o la heredera:

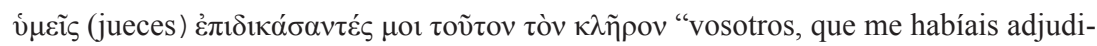
cado a mí esta herencia" (Is. 11.26)

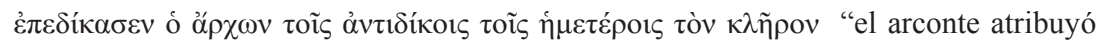
judicialmente la herencia a nuestros adversarios" (D. 48.26).

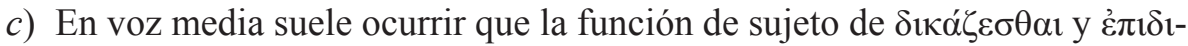
$\kappa a ́ \zeta \varepsilon \sigma \theta \alpha \imath$ no está desempeñada por los jueces o los magistrados, sino por los ciudadanos que son los que emprenden una acción judicial contra otro. Pero

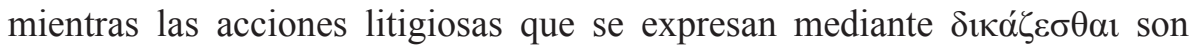

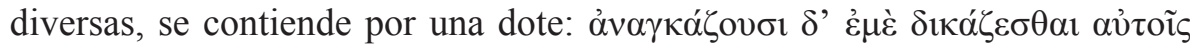
(D. 40.5) o por una suma que se adeuda, por lo cual es demandado Timoteo (D. 49.43), el compuesto se reserva para otras contiendas judiciales en situaciones de reivindicación de herencias y de epicleras.

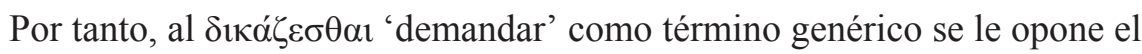

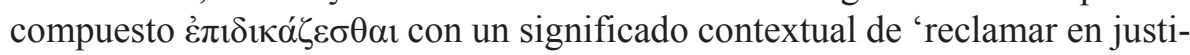
cia' los derechos sobre la heredera o la herencia; de ahí que la clase de persona que realiza esta acción suele ser el pariente que promueve una acción judicial para hacer valer sus derechos sobre la herencia o sobre la heredera.

En la oposición establecida con la agregación del preverbio, el vocablo compuesto quedó polarizado con un matiz técnico especial. Esa connotación jurídica diferente que poseen ambos términos es subrayada además por la construcción que les acompaña.

${ }^{21}$ Se está de acuerdo en que los magistrados competentes en la epidikasía eran los arcontes, mientras que hay cierta controversia respecto al papel de los jueces en este procedimiento. Sobre ello E. Karabélias, «Contribution à l'étude de l'épidicasie attique», Symposion 1974, AGR, Köln, 1979, sugiere que en la epidikasía se tendía a recurrir a un tribunal presidido por el arconte, p. 213. Cuando no había disputa, el arconte «publicaba el acta y velaba la ejecución», p. 218, cuando la había, era entonces necesario presentar las pruebas de parentesco ante los jueces, que lo estudiarían en profundidad, p. 220.

EMERITA (EM) LXXV 1, enero-junio $2007 \quad$ pp. 113-136 ISSN 0013-6662 
1) Sin preverbio suele llevar como régimen un dativo, pero no es infrecuente en forma absoluta o con genitivo que indica la causa por la que se promueve un proceso:

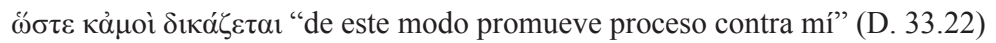

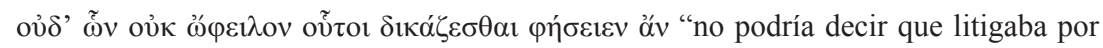
sumas que éstos no debían" (D. 36.21).

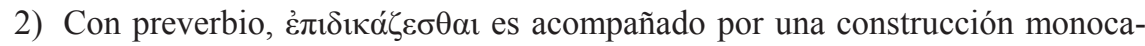
sual con genitivo que, sin duda, es de tipo judicial que designa el motivo por el que se contiende en justicia y ese genitivo puede ser de cosa o de persona,

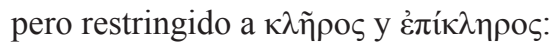

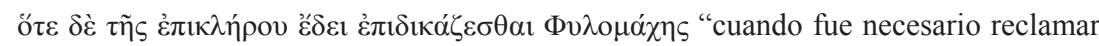
en justicia como epiclera a Filómaca" (D. 43.55) ${ }^{22}$

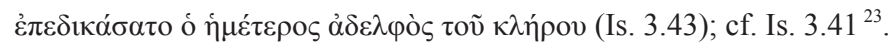

Pues bien, nos quedaría por examinar la connotación semántica que pue-

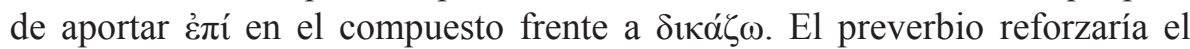
valor directivo al llevar un Dat. que especifica la persona que se beneficia de la adquisición de la herencia, cuando son los jueces o los magistrados los que realizan la acción de adjudicar la herencia, mientras que, cuando los ciudadanos desempeñan la función de sujeto, el preverbio entonces en un uso nocional subrayaría el matiz de hostilidad que todo proceso conlleva.

d) Esta restricción de sentido en la lengua judicial dio lugar a la consagra-

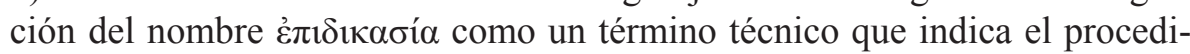
miento legal a través del cual el pariente más cercano, el anchisteus, demanda en justicia la herencia y la mano de la heredera ${ }^{24}$ :

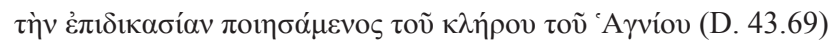

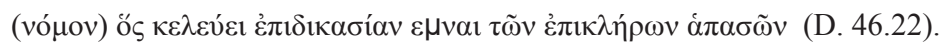

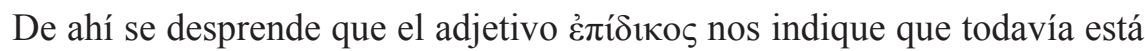
en curso el procedimiento de la epidikasia ${ }^{25}$, que la adjudicación de la heren-

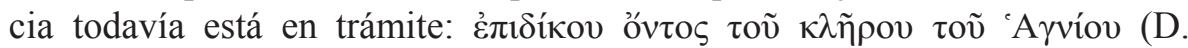
43.69).

22 Cf. Lys. Fr. 340.

23 Excepto en Is. 3.58, que aparece con el simple.

24 Beauchet, ob.cit., I, p. 442.

25 A.R.W. Harrison, The Law of Athens. The Family and Property, Oxford, 1968, p. 10.

EMERITA (EM) LXXV 1, enero-junio $2007 \quad$ pp. 113-136 ISSN 0013-6662 


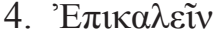

Del significado de 'llamar', tanto el simple como el compuesto pasaron pronto a formar parte del vocabulario religioso, denotando la invocación a los dioses, sin que el preverbio comportara diferencia de sentido:

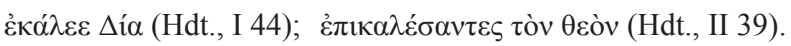

Posteriormente ambos entran en el lenguaje jurídico de los oradores sin renunciar a su sentido primero propio de la lengua común ${ }^{26}$, aunque se observa una tendencia creciente hacia el campo semántico judicial. Pero mediante el prefijo se produce una oposición semántica que repercute en el ámbito procesal, puesto que servirá para expresar acciones judiciales diferentes, 'citar' y 'demandar'.

a) El término simple se aplica, por lo general, a la citación judicial. En Demóstenes, como en Iseo, Lisias y Esquines, goza de un uso frecuente para designar el llamamiento a una persona por parte de las autoridades judiciales para que comparezca como testigo o no ante un tribunal. Con el arconte como sujeto aporta Demóstenes ejemplos:

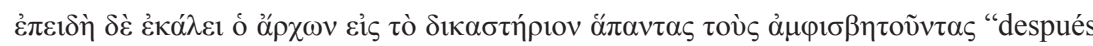
de que el arconte citó ante el tribunal a todos los reclamantes" (D. 48.25) ${ }^{27}$.

Pero lo más usual es encontrar en los oradores el simple cuando se quiere llamar a los testigos en un proceso (D. 18.135; Lys. 12.47; Is. 1.16; Aeschin. 2.54).

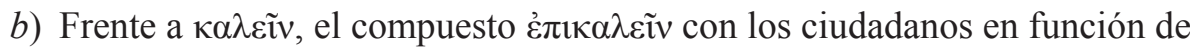
sujeto precisa la idea de 'demandar', 'poner una demanda'; aunque coexista con otro significado más común, desprovisto de sentido jurídico ${ }^{28}$. De esta manera en el lenguaje judicial se opera con la oposición de ambos términos para obtener diferentes significados que se pueden constatar en las leyes de Gortina:

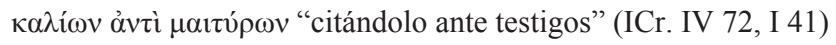

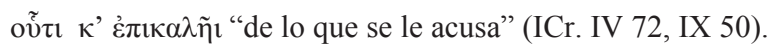

En los valores lexicales áticos entran en juego no sólo el preverbio, sino también la construcción para denotar una precisión legal diferente. Si el régi-

26 En D. 18.127 continúa el significado de 'invocar' a la inteligencia y a la educación.

27 Cf. D. 39.8; D. 19.211.

28 'Llamar de sobrenombre', en el que ha ejercido influencia el preverbio con una evidente connotación abstracta de acumulación 'nombre sobre nombre' (Aeschin. 3.181).

EMERITA (EM) LXXV 1, enero-junio $2007 \quad$ pp. 113-136 ISSN 0013-6662 


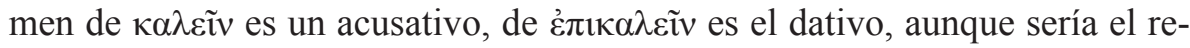
sultado de una locución abreviada, que aparece ya con anterioridad en Antifonte, 'llevar como una acusación algo contra alguien", 'acusar':

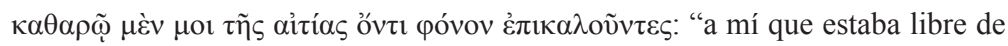
culpa me acusan de asesinato" (Antipho 4.2.7).

Después se restringe a la construcción monocasual con dativo, en la que el prefijo غ̇ंí modifica el sentido al agregar una noción de hostilidad, aunque es un empleo bastante escaso entre estos autores.

Del discurso demosténico Contra Calipo recogemos un ejemplo con el sentido judicial de 'poner una demanda'. Cuando el demandado, hijo de Pasión, se queja de las falsedades del próxeno Calipo, quien le había interpuesto un pleito después de fallecer su padre con el que sostenía ya un litigio, alega que él ofrece el juramento como marca la ley para probar la verdad:

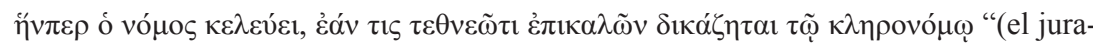
mento) que la ley prescribe si alguien, que sostenía una querella con uno y se muere, promueve un proceso contra el heredero" (D. 52.18) ${ }^{29}$.

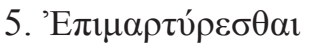

a) El contracto $\mu \alpha \rho \tau \cup \rho \varepsilon \tilde{v}$, no $\mu \alpha \rho \tau u ́ \rho \varepsilon \sigma \theta \alpha 1$, se impone en la lengua de los oradores como el término jurídico por excelencia para designar la acción de 'prestar testimonio', 'testificar', aunque aparezca tímidamente en discursos políticos, no jurídicos en un uso de la lengua común como sinónimo de 'probar' $^{30}$. Su construcción es variada, porque puede ir en forma absoluta, con Ac.: $\tau \dot{\alpha} \lambda \eta \theta \tilde{\eta} \mu \alpha \rho \tau \nu \rho \varepsilon \tilde{i v}$ (Aeschin. 1.46), con Dat. que representa la persona

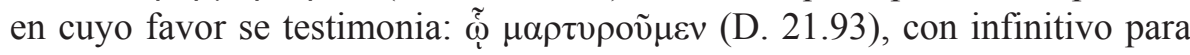
expresar, en este caso, las declaraciones que emite una persona sobre hechos que conoce:

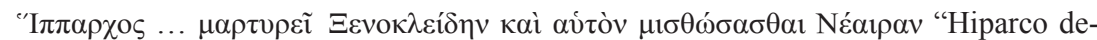
clara que Jenoclides y él alquilaron a Neera" (D. 59.28).

b) Por otro lado, es Demóstenes el orador que, basándose en el compuesto $\dot{\varepsilon} \pi \mu \alpha \rho \tau v ́ \rho \varepsilon \sigma \theta \alpha$, constituido, ahora, sobre el verbo $\mu \alpha \rho \tau v ́ \rho o \mu \alpha$, ofrece una

29 Esta acepción de $\dot{\pi} \pi 1 \kappa \alpha \lambda \varepsilon \tilde{\imath} v$ se testimonia en un documento epigráfico para indi-

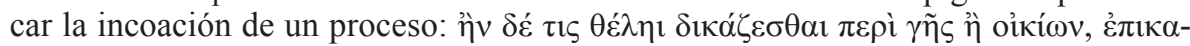

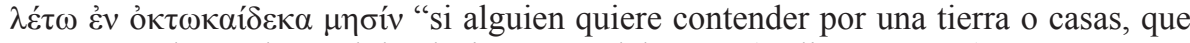
ponga una demanda en el día decimoctavo del mes”. (Halicar. I 17.23).

30 Cf. D. 20.130.

$$
\text { EMERITA (EM) LXXV 1, enero-junio } 2007 \quad \text { pp. 113-136 ISSN 0013-6662 }
$$


acepción mucho más específica que la de deponer testimonios, aprovechando las posibilidades expresivas del preverbio y empleándolo en voz media. Así mediante $\dot{\varepsilon} \pi \mu \alpha \rho \tau u ́ \rho \varepsilon \sigma \theta \alpha$ el orador subraya que el sujeto tiene interés en hacerse con testigos y reunir testimonios, para que declaren lo que han presenciado o saben sobre él.

El que pronuncia el discurso Contra Evergo y Mnesibulo dice que, al ser golpeado por Teofemo, recoge los testimonios de los que estaban presentes:

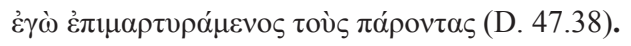

En Contra Formión se nos informa de que aquellas personas que recibían préstamos, cuando "salían de los emporios ponían a su lado a muchos para tomarlos como testigos de que...":

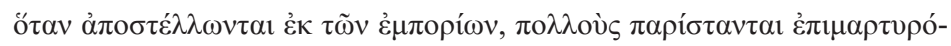
$\mu \varepsilon v o$ ö $\tau$.... (D. 34.28).

En la misma línea Sosíteo, en Contra Macártato, para probar la verdad de que unos sujetos arrancaron unos olivos de las tierras de Hagnias, toma como testigos a unos vecinos y a otros que convocaron, "cuando estábamos procediendo a recabar testimonios sobre esto":

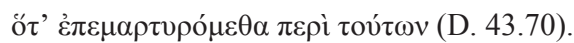

Pues bien, dado que el compuesto con ė $\pi$ í es utilizado en un contexto similar, cuando una persona tiene intención de reunir testigos para que depongan su testimonio ${ }^{31}$, parece que el preverbio aportaría una connotación determinada al verbo, más allá de su significado de 'testificar', tal vez, en un uso abstracto, añada el valor de acumulación, derivado de su valor 'sobre', es decir, "unas declaraciones sobre otras' ${ }^{32}$, con lo cual a través del compuesto se nos transmite la idea de que el sujeto se sirve de otras personas para acumular más testimonios que apoyen su propia testificación.

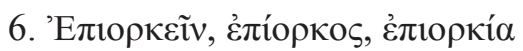

Asistimos a unos términos que en la oratoria adquieren un uso preferentemente jurídico y que nos corroboran que el procedimiento prefijal hacía posible transmitir a un mismo lexema matices diferentes. Demóstenes opera con

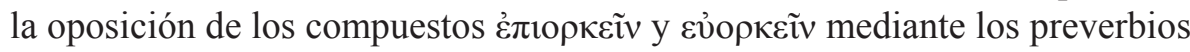

\footnotetext{
31 Cf. también D. 55.7.

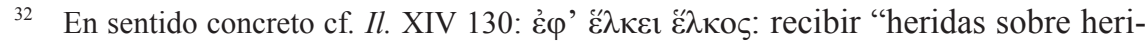
das".
}

EMERITA (EM) LXXV 1, enero-junio $2007 \quad$ pp. 113-136 ISSN 0013-6662 
para conferirles contenidos opuestos: 'perjurar' frente a 'jurar con verdad'.

En Contra Conón se percibe con nitidez esta diferencia de sentido al oponerse ambos verbos:

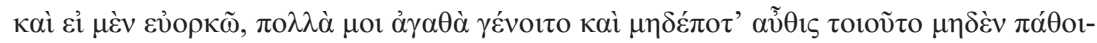

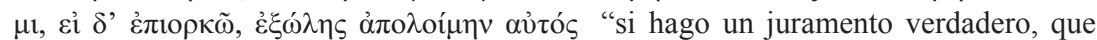
haya muchos bienes para mí y nunca sufra de nuevo nada de esto, pero si juro en falso, perezca yo mismo aniquilado" (D. 54.41).

a) En el lenguaje jurídico por 'perjurar' se entiende tanto 'jurar en falso' como 'quebrantar un juramento'. Estos dos conceptos los encontramos recogidos por Demóstenes en el término غ̇лıоркєĩ 1) 'jurar en falso' sabiendo que lo que se jura no es verdad, 2) 'incumplir un juramento':

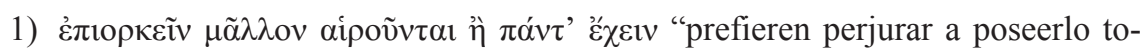
do" (D. 57.53). El que se defiende en este litigio atestigua que unos sujetos han jurado en falso respecto a su persona, porque calumnian sobre su linaje.

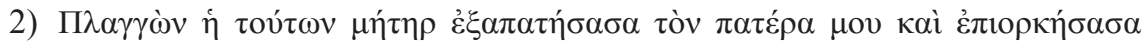

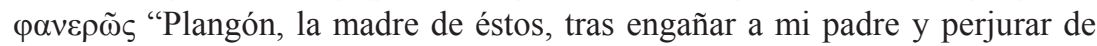
un modo manifiesto" (D. 40.2). El perjurio de Plangón consistió en un quebranto del juramento, puesto que convino mediante juramento con el padre del demandante que, si éste reconocía a sus hijos, cuando le requiriera ante el árbitro a que jurara si habían nacido de él, ella se negaría al requerimiento. Después Plangón violó el juramento, porque juró precisamente lo contrario de lo que había prometido.

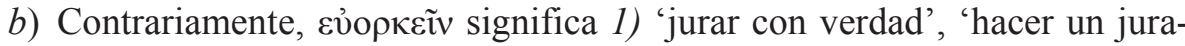
mento verdadero', como hemos visto en D. 54.41 y 2) sobre todo, 'respetar lo jurado', que suele tener como sujeto los jueces o los heliastas: ’̀v घủopкoín$\tau \varepsilon \ldots, \delta 1 \kappa \alpha \sigma \tau \alpha i$ : 'respetaríais el juramento, jueces' (D. 57.69); cf. D. 39.37.

Ahora bien, si claros son los contenidos semánticos que ambos verbos expresan, la dificultad mayor estriba en determinar cuál es el valor que apor-

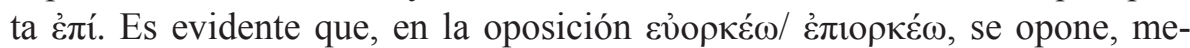
diante $\varepsilon \dot{v}$ y $\varepsilon$ źí, lo verdadero de lo falso.

c) Esta misma oposición semántica se observa en otra clase de palabra,

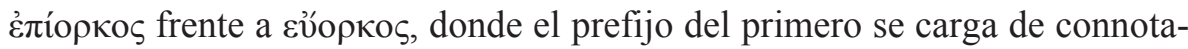

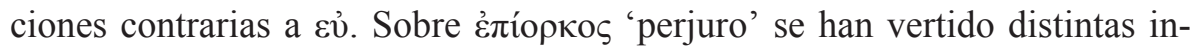

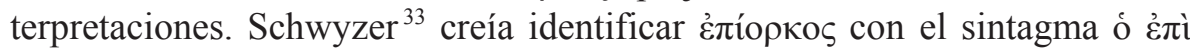

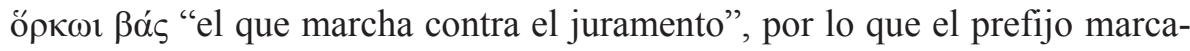

33 Cf. E. Hoenigswald, «EPIORKOS», SIFC 14, 1937, p. 83.

$$
\text { EMERITA (EM) LXXV 1, enero-junio } 2007 \quad \text { pp. 113-136 ISSN 0013-6662 }
$$


ría una idea de hostilidad. Frisk duda de que el prefijo غ̇ंí aporte esta noción 'contra'. Para Chantraine ${ }^{34}$ la tesis menos improbable es la de Benveniste que piensa que "ajouter (à son dire) un serment" viene a significar "hacer un falso juramento".

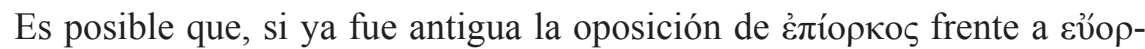
$\operatorname{\kappa os}^{35}$, en el verbo denominativo hubiera ocurrido lo mismo y el preverbio $\varepsilon \dot{\pi}$ í habría tomado también un sentido negativo; de ahí el verbo compuesto por polarización llegó a significar 'jurar en falso'.

El ejemplo de Plangón podría servirnos para entender ese valor adquirido de żлí cuando ella perjura, puesto que no juró lo que mediante juramento antes había prometido a su amante que declararía, sino que después hizo un juramento contrario al primero:

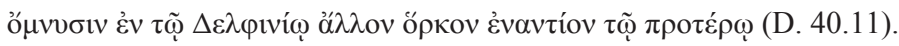

Entiendo que sería un juramento 'sobre' otro juramento, por lo que uno de ellos resultaría falso y de ahí esa connotación tan precisa de 'jurar en falso'.

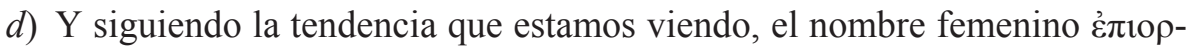
кía se consagra como el tecnicismo jurídico que indica el delito de perjurio:

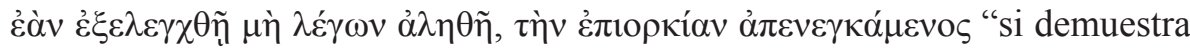
que no dice la verdad, incurriendo en perjurio...” (D. 23.68).

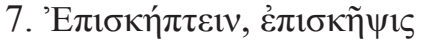

Es evidente la polisemia de este verbo que reposa sobre recursos sintácticos y de prefijación, los cuales fueron aprovechados por los oradores áticos para definir distintos actos jurídicos.

a) En voz media el simple $\sigma \kappa \eta ́ \pi \tau \varepsilon \sigma \theta \alpha 1$, cuyo significado es 'apoyarse' ${ }^{36}$, fue utilizado por los oradores para designar acciones abstractas más ajustadas a contextos jurídicos, abandonando su sentido concreto de la lengua común.

$\mathrm{Si}$ atendemos a los determinantes verbales, veremos que el verbo, precisado por dativo de persona y complemento predicativo, se emplea para indicar la acción de servirse de alguien con objeto de que confirme la veracidad de

34 P. Chantraine, Dictionnaire étymologique de la langue grecque, Paris, 1968, p. 821.

35 Cf. Hoenigswald, ob. cit., p. 85.

36 Según Chantraine, ob. cit., p. 1016, «todos los empleos del verbo proceden del sentido de 'apoyarse' o 'apoyarse sobre'».

EMERITA (EM) LXXV 1, enero-junio $2007 \quad$ pp. 113-136 ISSN 0013-6662 
los hechos ante un juez, concretamente "apoyarse en alguien como testigo".

Demóstenes evidencia este significado cuando nos dice que el comerciante Formión se apoyó en Lampis como testigo, para que atestiguara que había pagado el préstamo:

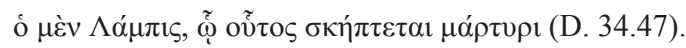

b) También en voz media, pero con otra construcción, esta vez con infinitivo como complemento, $\sigma \kappa \eta ́ \pi \tau \varepsilon \sigma \theta \alpha$ adquiere en contextos legales ${ }^{37}$ el significado de 'alegar', 'pretextar'. En su descargo, Aristocles, que en un litigio comercial había sido designado árbitro y, por tanto, depositario de un contrato,

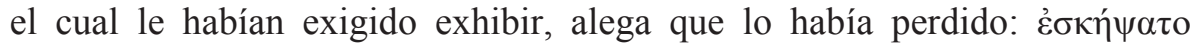
$\alpha \dot{\alpha} \pi \lambda \omega \lambda \varepsilon \dot{\varepsilon} \alpha \alpha$ (D. 33.18). De la misma acepción hace uso Iseo: $\Lambda \eta \mu v i ́ \alpha v$

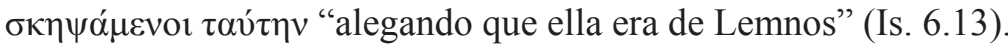

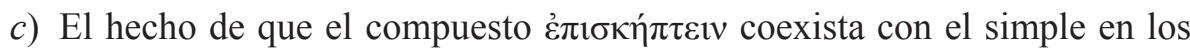
discursos de los oradores nos permite confirmar de nuevo que la prefijación fue un modo bastante recurrente para obtener acepciones jurídicas diferentes, aprovechando los distintos valores del uso nocional que ofrece el preverbio.

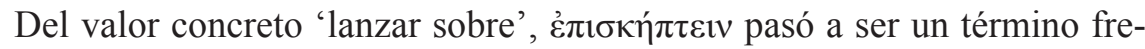
cuente en el lenguaje legal ateniense cuando se hacía referencia a cuestiones

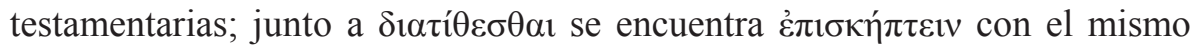
significado de 'disponer por testamento'. Ambos designaban la acción de una persona que realiza su última disposición, pero el segundo tenía connotaciones algo más precisas. Mediante este verbo en voz activa se entendía que el difunto declaraba su última voluntad y ordenaba que se cumpliera una serie de actos después de su muerte, pero su orden era unilateral, es decir, se habría de cumplir por obligación. El causante imponía su voluntad a sus familiares que estaban obligados a realizarla ${ }^{38}$.

En este sentido el verbo que va en activa y construido con dativo más infinitivo implica una idea de autoridad que se ejerce sobre alguien y que viene expresada por el valor 'sobre', aunque en figurado, del preverbio غ̇ $\pi$ í.

Iseo testimonia esta acepción, cuando menciona la disposición que hizo

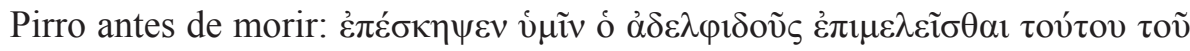

37 Cf. Lys. 4.14.

38 F. Sanmartí Boncompte, «'E $\pi \_\kappa \eta ́ \pi \tau \varepsilon ı v$ y $\delta \iota \alpha \tau i ́ \theta \varepsilon \sigma \theta \alpha 1 »$, Studi in onore di Ugo Enrico Paoli, Firenze, 1956, p. 630 ss.

EMERITA (EM) LXXV 1, enero-junio $2007 \quad$ pp. 113-136 ISSN 0013-6662 
$\pi \alpha 1 \delta$ íov (Is. 3.69) ${ }^{39}$.

Demóstenes alude al momento en que su padre se sintió enfermo y reuniendo a los allegados les ordenó que arrendaran la casa: غ̇ंı

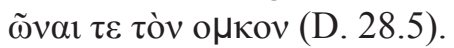

d) En otros contextos el compuesto غ̇ंıкń $\pi \tau \varepsilon \sigma \theta \alpha \imath$ en voz media tomó el sentido jurídico de 'querellarse', muy usado en el lenguaje procesal. En este caso lleva como régimen un dativo de persona y un genitivo que indica el motivo de la querella, un genitivo judicial, aunque también puede aparecer en forma absoluta. Ahora el preverbio ha agregado al lexema verbal, en un uso nocional, una connotación semántica diferente, que se relaciona con una

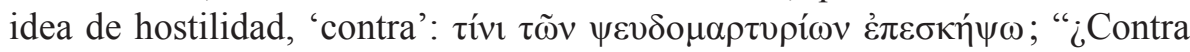
quién te querellaste por falsos testimonios?" (D. 29.41).

Por causa del falso testimonio de Leócares se emprende una acción judicial que se expresa mediante este verbo:

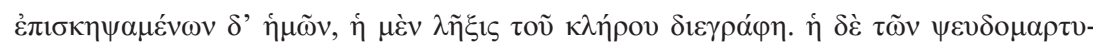

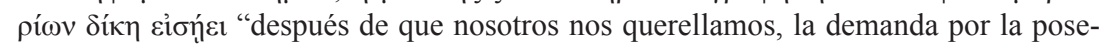
sión de la herencia fue retirada y la acción por falsos testimonios comenzó" (Is. 5.17).

Ahora bien, según LSJ y Chantraine ${ }^{40}$ este verbo se empleaba en casos de denuncia por falso testimonio. En efecto, este es el motivo de la acción judicial contra Leócares, como el de otros muchos casos que presentan los oradores $^{41}$, pero parece que este término no estuvo restringido a delitos por falso testimonio, sino que en alguna ocasión sirvió también para indicar la acusación por homicidio, como en Lys. $3.39^{42}$.

e) Es claro que esta dualidad de significado transmitida por el prefijo habría de ser recogida también por el nombre غ̇ंıкñ $1 \varsigma$ y así el término es empleado en los textos legales en sus dos acepciones: 1) en la de iniunctio o adjura-

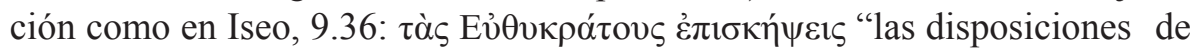
Eutícrates"; 2) con el sentido de 'querella' $\psi \varepsilon v \delta o \mu \alpha \rho \tau v \rho i ́ \omega v ~ \varepsilon ̇ \pi ı \sigma \kappa \eta ́ \psi \varepsilon เ \varsigma$ (Is. 4.17).

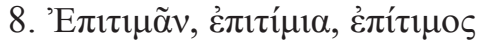

La familia etimológica de $\tau \mu \alpha ́ \omega$ y sus derivados fue muy productiva en los

39 Cf. Is. 3.71, 73; 9.19.

40 Chantraine, ob. cit., p. 1016.

$41 \quad$ D. 29.7 , 10; D. 48.45 : D. 52.28. Is. 3.11; Is. 5.9

42 R. Renehan, «Greek Lexicographical Notes: Fifth Series», Glotta 50, 1972, p. 47.

EMERITA (EM) LXXV 1, enero-junio $2007 \quad$ pp. 113-136 ISSN 0013-6662 
textos legales. Razones distribucionales y de prefijación son los factores que han influido en la adquisición de significados diferentes, incluso contrarios.

a) La noción de estimación está presente no sólo en el simple $\tau \mu \tilde{\alpha} v$, sino también en el compuesto con غ̇ंí por tratarse de un denominativo formado sobre el sustantivo $\tau \iota \mu$ ' 'estimación', 'valor'. En un principio $\tau \mu \alpha \tilde{\alpha} v$ es un término ajeno al vocabulario jurídico, porque prevalece su acepción de estimación que se traduce en su significado de 'honrar', más apropiado al campo de la política. Sin embargo, irrumpe en el lenguaje de los oradores con un valor propiamente jurídico en el que intervienen hechos contextuales, dado que la temática de sus discursos incide en gran manera en las estimaciones que los jueces hacían de los delitos o las penas correspondientes y aparece, entonces, el significado de 'estimar digno de' muerte, por ejemplo en D. 24.103, aunque se mantienen ambos usos pertenecientes al campo político ${ }^{43}$ o legal. La ley que recoge Demóstenes en C. Macártato evidencia su uso jurídico:

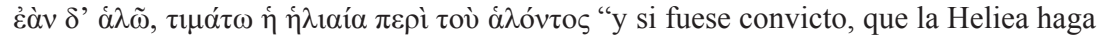
la estimación en torno al condenado" (D. 43.75) ${ }^{44}$.

Esta significación no se limita al verbo, sino, como era de esperar, tam-

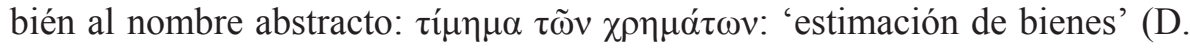
29.8).

b) Respecto al compuesto hay que observar que, al prefijarlo con غ̇ंí los oradores tienden a menudo a dotarlo de un nuevo sentido con un valor de hostilidad que es precisado por el preverbio como fue 'censurar', un concepto que ya no concierne al ámbito legal ${ }^{45}$.

c) De la misma manera que el simple, en estos autores el compuesto va adquiriendo un componente legal, derivado de su primigenio valor de estimación ${ }^{46} \mathrm{y}$, aunque existe algún caso aislado aplicado a cuestiones de estimaciones propias de la lengua común, como p. ej. el trigo (D. 50.6) ${ }^{47}$, servirá también para expresar las que hacían los jueces sobre algún delito. De ahí que $\dot{\pi} \pi \imath \tau \mu \tilde{\alpha} v$ adquiriera el significado de 'imponer' una pena (1) o de 'fijar' una multa (2), donde el prefijo confería la idea de autoridad en su valor 'so-

43 Cf. D. 20.15.

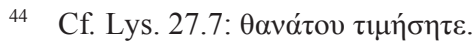

45 Cf. D. 18.162; Is. 2.37; Aeschin. 2.79; Lys. 22.17.

46 Hdt., VI 39: 'gratificar'.

47 Se refiere al trigo que estaba más valorado, se encarecía.

EMERITA (EM) LXXV 1, enero-junio $2007 \quad$ pp. 113-136 ISSN 0013-6662 
bre', expresando una relación vertical que toda jerarquía implica:

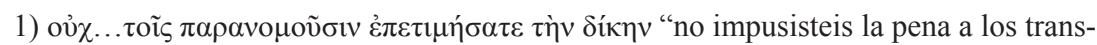
gresores" (D. 12.2).

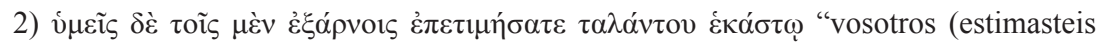
dignos de un talento) multasteis con un talento a cada uno de los que se negaban" (Aeschin. 1.113).

d) Y si es menos frecuente en los oradores $\dot{\varepsilon} \pi \tau \imath \mu \tilde{\alpha} v$ con sentido de 'imponer una multa', en cambio, el sustantivo derivado, sobre todo, en plural, غ̇ंı $\tau^{\prime} \mu 1 \alpha$, se consolida como término legal para designar las 'penas' o 'multas':

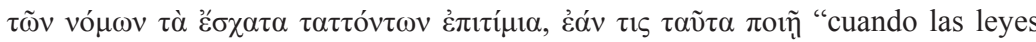
imponen los castigos más severos, si alguien hace esto" (D. 19.133) ${ }^{48}$.

Por lo general, cuando este término aludía a multas, éstas se diferencia-

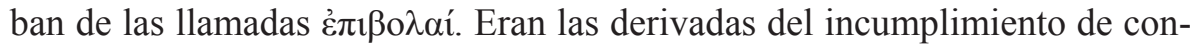
tratos, cuyo montante quedaba estipulado por las partes, cuando el deudor

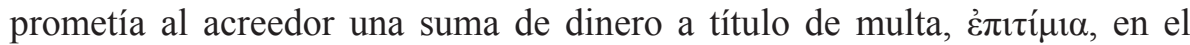
caso de que él no cumpliera sus obligaciones de devolución, un ejemplo cla-

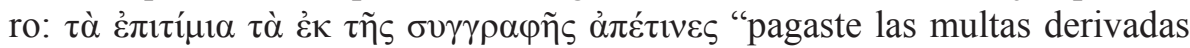
del contrato" (D. 34.26); cf. D. 35.46.

Pero también se trataba de multas ${ }^{49}$ que las leyes imponían a los que transportaban trigo fuera de Atenas (D. 34.37) o a quienes se retrasasen en la prestación de su servicio de trierarco (D. 50.57).

e) Ahora bien, la oposición lexical marcada por el prefijo se utilizó con profusión en cuestiones relativas al estado y la comunidad cívica. Mediante los

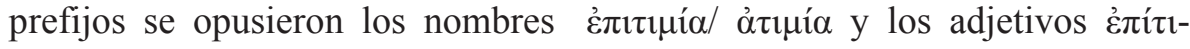

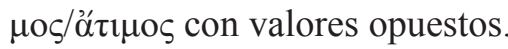

'E $\pi i ́ \tau \mu \rho \varsigma$ se refiere a una persona que adquiere, acumula todos los derechos y privilegios de ciudadano por oposición al ó́turos que no los posee:

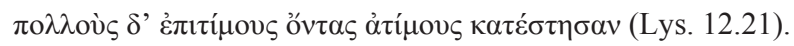

Frente a la $\alpha$ privativa, el $\dot{\varepsilon} \pi$ í tiene un uso nocional con idea de acumulación que repercute en su significado de "disfrute de los derechos cívicos", opuesto a su privación.

48 También en Aeschin. 1.14, 20 sobre las penas impuestas por los delitos sexuales de proagogía y de prostitución.

49 Cf. Is. 3.47. En época helenística se fija este significado de 'multa', como documenta el testamento de Epicteta de Tera, donde designa la multa que debe pagar quien no ha prestado servicios dentro de la asociación que ella funda (IG XII 3.330, 211).

EMERITA (EM) LXXV 1, enero-junio $2007 \quad$ pp. 113-136 ISSN 0013-6662 


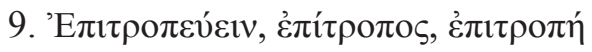

Asistimos a una familia léxica respecto a la cual intervienen de forma clara hechos contextuales en la precisión de su significado. Es evidente que el campo semántico de estos términos está centrado en la noción de "vigilancia", "cuidado" y con el prefijo se expresa la noción "sobre" quien se ejerce la vigilancia.

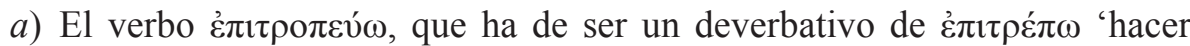
tomar una dirección', tiene siempre en la lengua de los oradores el significado jurídico de 'ser tutor' de huérfanos, aunque Platón lo emplea a la vez en otro sentido que cae fuera de la esfera jurídica 'asignar' ${ }^{50}$. Va determinado por un Ac. de objeto externo que indica la persona sobre la que se ejerce la

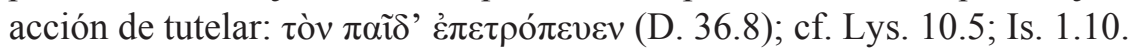

b) De igual modo corresponde a غ̇ $\pi i ́ \tau \rho о \pi \circ \varsigma^{51}$, otra clase de palabra, el significado de 'tutor', especialmente de huérfanos ${ }^{52}$, pero Esquines lo emplea para calificar a Ptolomeo como "regente de los asuntos públicos" غ̇ंít $\tau \tilde{\omega} v \pi \rho \alpha \gamma \mu \alpha ́ \tau \omega v$ (Aschin. 2.29).

c) Es el nombre غ̇лıтроли́ el término, cuya acepción depende exclusivamente del contexto. Cuando los oradores se están refiriendo a cuestiones de huérfanos significa 'tutela' (D. 29.6) ${ }^{53}$, pero, cuando abordan temas sobre litigios particulares, equivale a 'arbitraje', en alusión al árbitro que se nombra para estas ocasiones antes de pasar la disputa a los tribunales (D. 7.36) ${ }^{54}$.

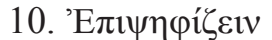

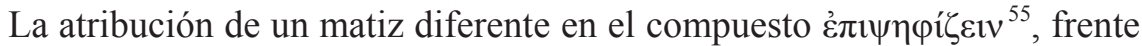
al simple $\psi \eta \varphi$ '́̌ $\varepsilon v^{56}$ 'votar', que se trata de un neologismo jurídico ${ }^{57}$, está en

50 M. Lebel, «Observations sur le vocabulaire juridique de Platon dans les lois», Melanges E. Delebecque, Aix-en-Provence, 1983, p. 241.

51 El sustantivo es muy usado en época helenística para cargos institucionales.

52 Cf. D. 27.15; Is. 1.10; Lys. 32.22.

53 Cf. D. 27.39; 29.30

54 Cf. D. 33.14, 16, 19, 23.

55 Este compuesto no es empleado ni por Lisias ni Iseo.

56 Este término se consagra en la lengua jurídica para designar la acción de 'votar' en

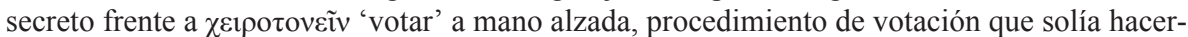

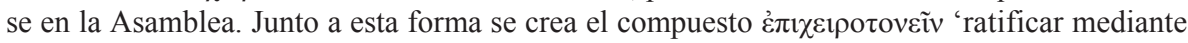
voto', a mano alzada, una proposición o un cargo, Esta acepción viene determinada por el uso temporal, no infrecuente, de este preverbio con el valor 'después'. Es decir, una votación so-

EMERITA (EM) LXXV 1, enero-junio $2007 \quad$ pp. 113-136 ISSN 0013-6662 
función del agente que realiza la acción, pero quizás con la adición del preverbio se pretendió además subrayar otra connotación semántica determinada que lo diferenciara de la simple acción de votar. En la oposición que se establece entre ambos, el compuesto se polariza con el sentido factitivo de 'hacer votar', 'poner a votación', al tener como sujeto una autoridad, los proedros, los presidentes del Consejo o de la Asamblea y los arcontes, cuya función consistía en someter a votación las propuestas:

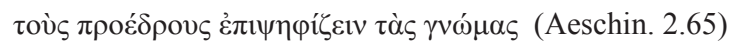

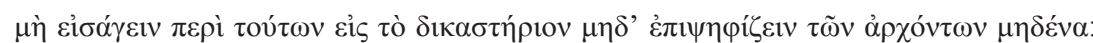
"que ningún magistrado lleve ante el tribunal (causas judiciales) acerca de esto ni proponga ninguna votación” (D. 24.54).

Así con el procedimiento de la composición se distinguían dos actos diferentes de un mismo proceso. No es clara la aportación que el prefijo hace al lexema verbal, pero quizás incida en la noción de autoridad que estas personas conllevan en la idea de que van a imponer la votación "sobre", lo que representa una relación vertical con los votantes.

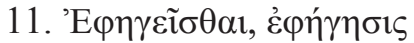

Con el verbo se nos indica en derecho ático la conducción de un magistrado al lugar del delito donde se oculta el culpable. Es la acción jurídica conoci-

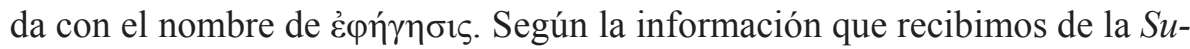

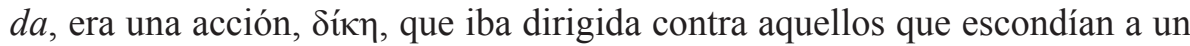
criminal o un fugitivo, pero también contra los que ocultaban alguna propiedad pública ${ }^{58}$. Demóstenes es el único de los oradores áticos que alude a esta acción legal y lo hace mediante la forma verbal y en muy pocas ocasiones.

Construído, igual que el verbo simple ( $\dot{\eta} \mu \tilde{v} v \dot{\eta} \gamma \varepsilon i ́ \sigma \theta \omega:$ Od. XXIII 134),

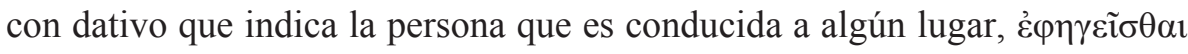
adopta la forma compuesta para convertirse en un nuevo tecnicismo al opo-

bre otra, una después de otra, (D. 24.39). Hemos preferido introducirlo en nota por tratarse, sobre todo, de votaciones de carácter político, siendo consciente de la dificultad de delimitar el campo propiamente jurídico, cf. A. R. Navarrete Ocera, «Confección de un léxico jurídico griego», EMERITA 59, 1991, pp. 352-357, que nos informa de su tesis doctoral inédita sobre el Léxico jurídico de Demóstenes.

57 Sobre este neologismo, cf. J. Ma . Lucas, ob. cit., pp. 197, 199.

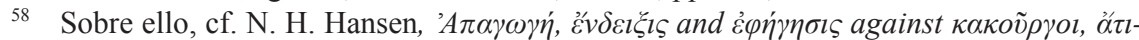

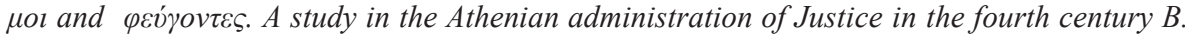
C., Odense, 1976.

$$
\text { EMERITA (EM) LXXV 1, enero-junio } 2007 \quad \text { pp. 113-136 ISSN 0013-6662 }
$$


nerse al simple 'conducir' mediante el preverbio غ̇ $\pi$ í. En realidad, en cuanto al significado propio en nada difiere el simple del compuesto, el preverbio tan sólo reforzaría, en un uso local, el valor 'cerca' expresando el contacto estrecho, pero, al coexistir las dos verbos, el compuesto se adscribió al campo de la terminología legal, mientras que el simple mantenía sus acepciones propias de la lengua común.

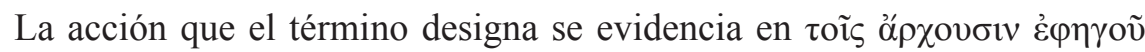
(D. 22.26), cuando Demóstenes está describiendo los procedimientos legales griegos, pero en forma absoluta tiene el mismo uso jurídico cuando en el discurso $C$. Aristogitón II alude al hecho de que alguien que interpone una demanda judicial y no obtiene una quinta parte de los votos, la ley no permite "ni que se emprenda una acción contra él, ni apresarlo, ni llevarle los magis-

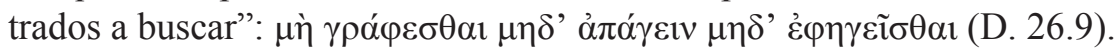

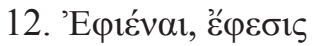

Otro verbo cuyo preverbio aportó connotaciones precisas al significado

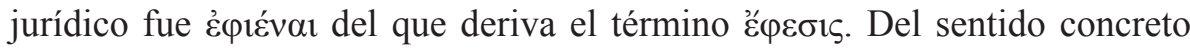
'enviar' pasó al argot jurídico con la acepción de 'recurrir', 'apelar', aunque no fue su uso preferente y continuó expresando acepciones de la lengua común. 'Е $\varphi \varepsilon \sigma 1 \varsigma$, en cambio, quedó consagrado como vocablo técnico para designar la apelación. De los oradores es Demóstenes quien hace uso de él, pero Aristóteles (Ath. 9) testimonia también su significado.

Si nos fijamos, 'recurrir' no significa otra cosa que "demandar una nueva revisión judicial", un juicio posterior. Y dado que la apelación es un recurso posterior contra una decisión anterior, me parece que en el prefijo no hay ni uso local ni nocional, sino un uso temporal que la lengua griega utiliza con no poca frecuencia. Considero que tiene un valor temporal 'después' en sen-

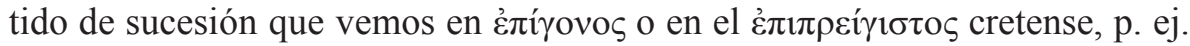
Además si tuviera un uso local con valor 'cerca', 'hacia', se hubiera prefijado con siç, como en Esquines $2.14^{59}$, y además la idea de dirección está reforzada por el sintagma preposicional que lo completa.

Así Beoto que había sido condenado en un proceso, una vez oído el dictamen del árbitro, no hizo una apelación al tribunal para que se revisara su

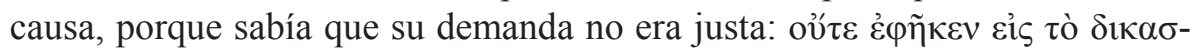

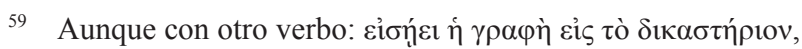

EMERITA (EM) LXXV 1, enero-junio $2007 \quad$ pp. 113-136 ISSN 0013-6662 


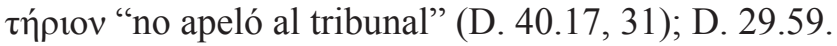

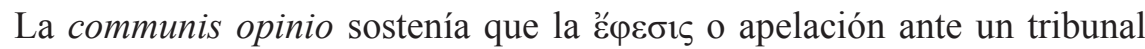
tenía por objeto la enmienda o anulación de una sentencia emitida por uno inferior. No obstante, según Paoli, hay una diferencia de matiz. Para este in-

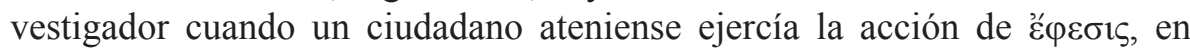
realidad significaba que rechazaba la decisión de un magistrado y tenía el derecho de ser juzgado de nuevo por un tribunal popular ${ }^{60}$, la Heliea, que era la base y el poder de la democracia. De esta manera entiendo que el ciudadano ateniense tenía la posibilidad legal ${ }^{61}$ de remitir el caso 'después', 'posteriormente' ( $\dot{\varepsilon} \pi \hat{)}$ a un tribunal para que lo juzgara.

Esta matización se puede apreciar en el discurso C. Eubúlides de Demóstenes donde se alude a la exclusión de derechos de ciudadanía que padece el mismo Eubúlides por parte de los demotas quienes decidían sobre este asunto, pero la ley ateniense permitía que los excluidos pudieran apelar ejerciendo la $̌$ $\varphi \varepsilon \sigma ı \varsigma$ ante un tribunal de los Heliastas. De esta forma se dirige el de-

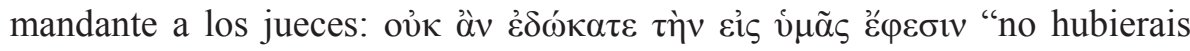
permitido la apelación ante vosotros" (D. 57.6).

A modo de conclusión diremos que la lengua jurídica ha jugado con las posibilidades que los valores del preverbio y la distribución le ofrecían para precisar su vocabulario. Como era de esperar el uso más general del preverbio fue el nocional o abstracto abundando el valor que expresa una idea de hostilidad y autoridad, dado el contexto procesal en que se encontraba, aun-

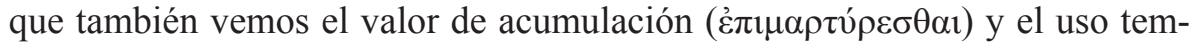

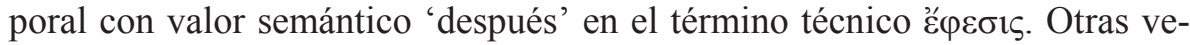
ces en la precisión semántica del vocablo además del prefijo ha influido la persona que representa el emisor y el receptor y también la oposición activa

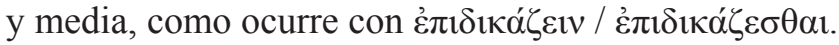

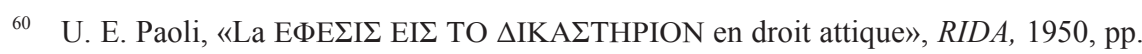
$335,337$.

${ }_{61}$ Los documentos epigráficos áticos del siglo V se hacen eco también de este derecho,

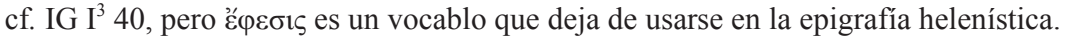

EMERITA (EM) LXXV 1, enero-junio $2007 \quad$ pp. 113-136 ISSN 0013-6662 
Con arreglo a las normas editoriales vigentes para las publicaciones periódicas del CSIC, se hace constar que el original definitivo de este artículo se recibió en la redacción de EMERITA en el primer semestre de 2007, tras haber sido aprobada su publicación en ese mismo período (06.05.07 - 14.01.07)

EMERITA (EM) LXXV 1, enero-junio $2007 \quad$ pp. 113-136 ISSN 0013-6662 